\title{
The Differentiate Effect of Self-Efficacy, Motivation, and Satisfaction on Pre-Service Teacher Students' Learning Achievement in a Flipped Classroom: A Case of a Modern Educational Technology Course
}

\author{
Li Zhao $^{1}\left(\mathbb{D}\right.$, Xiaohong Liu $^{1}(\mathbb{D})$ and Yu-Sheng Su ${ }^{2, *}$ \\ 1 School of Education Science, Nanjing Normal University, Nanjing 210097, China; li.zhao@njnu.edu.cn (L.Z.); \\ xiaohongliu1211@gmail.com (X.L.) \\ 2 Department of Computer Science and Engineering, National Taiwan Ocean University, \\ Keelung 202301, Taiwan \\ * Correspondence: ntoucsiesu@mail.ntou.edu.tw or ntouaddisonsu@gmail.com
}

check for

updates

Citation: Zhao, L.; Liu, X.; Su, Y.-S. The Differentiate Effect of

Self-Efficacy, Motivation, and

Satisfaction on Pre-Service Teacher Students' Learning Achievement in a Flipped Classroom: A Case of a Modern Educational Technology Course. Sustainability 2021, 13, 2888. https://doi.org/10.3390/su13052888

Academic Editor: Sandro Serpa

Received: 2 February 2021

Accepted: 4 March 2021

Published: 7 March 2021

Publisher's Note: MDPI stays neutral with regard to jurisdictional claims in published maps and institutional affiliations.

Copyright: (c) 2021 by the authors. Licensee MDPI, Basel, Switzerland. This article is an open access article distributed under the terms and conditions of the Creative Commons Attribution (CC BY) license (https:/ / creativecommons.org/licenses/by/ $4.0 /)$.

\begin{abstract}
To analyze how variability changes over time can enhance the understanding of how learners' self-efficacy, motivation, and satisfaction is controlled and why differences might exist among groups of individuals. Therefore, this study compared the effect of variability on pre-service teacher students in the flipped classroom approach with a course named modern educational technology (MET). In total, 77 students in two groups participated in this study. Learners in the experimental group received the flipped classroom treatment. Learners in the control group received the traditional lecture-centered instructional approach. The learning outcomes were evaluated by practice assignment, transfer assignment, and student perception survey. The survey includes the evaluation of learning satisfaction, self-efficacy, and learning motivation. Pre-test and post-test were conducted by the two groups. The data analysis results applied analysis of variance (ANOVA) or analysis of covariance (ANCOVA) and revealed that the experimental group displayed a better learning achievement than the control group. The experimental group participants' perception also showed variability (i.e., learning satisfaction, self-efficacy, and learning motivation) was better than the control group. Considering the overall study results, the flipped classroom model can be applied in the pre-service teacher students' modern educational technology course.
\end{abstract}

Keywords: flipped classroom; pre-service teacher students; modern educational technology; learning satisfaction; learning motivation; self-efficacy

\section{Introduction}

According to national teacher certification requirements, teachers need to master digital technology and be able to use it in classroom teaching [1]. Therefore, many educational technology policies focus on developing teacher education, so that technology can be effectively integrated into pre-service teacher education [2,3]. Considering this, the modern education technology (MET) course is a compulsory course for all pre-service teacher students in China and to develop the knowledge and skills of technology integration for teachers and students in the classrooms. However, "teacher-demonstrating while student-practicing" and instillation teaching is still the regular phenomenon in the MET classroom [4]. This model cannot stimulate students' interest and subjective initiative in learning and has little benefit on students' learning effect [5]. It is inevitable to adopt innovative teaching methods to convert traditional teaching methods into digital presentations [6].

However, based on digital presentation (e.g., posting quality videos in the classroom) to develop skills and knowledge for the integration, it has emerged that educators generally lack the attitude and competencies to meet this challenge of learning modern technology [7]. 
On the other hand, the flipped classroom model as a well-developed model supported by Massive Open Online Courses (MOOCs) and the widely recognized pedagogical strategy have been increasingly implemented in various higher education subjects [8]. While preservice teacher students acquire experience of learning modern technology in Chinese teacher education programs, little is studied in the direction of using the flipped classroom approach. For this reason, there can be a gap between the general digital learning approach and the flipped classroom approach for pre-service teacher students' experiences. Their achievement emotion needs further study in the Chinese context.

Cognitive-affective theory of learning with media [9] conceptualizes new types of media learning in a framework combining cognitive and affective aspects. To examine the affective factors, the control value theory of achievement emotions refers to learning achievement-related emotions [10]. It can be differentiated by their belief in self-efficacy, which functions as an indicator of control cognitions [11,12]. In the present study, assumptions of achievement emotion are transcribed into an experimental study design and are investigated concerning their motivation and satisfaction. Moreover, considering the learning achievement emotion, prior studies showed that whether the flipped classroom model has positive effects on students' emotion is not conclusive yet [13-20]. Further research still needs to explore into whether the flipped classroom approach brings better learningrelated emotions and outcomes to students. Particularly, few studies exploring flipped classrooms were used in the MET course in China [5]. In line with this, this study focuses on exploring the students' learning achievement, learning satisfaction, learning motivation, and self-efficacy by applying the flipped classroom approach in the MET course.

Immersing pre-service teacher students into student-centered flipped classroom learning will help them prepare for effective teaching in the future classroom [21]. Expectedly, a deeper understanding of this information can bring us closer to the optimal circumstances for learners in the similar course, and the findings of the current research can be applied to comparable situations. In addition, understanding these issues can provide ideas for the design of teacher education programs to develop an appropriate curriculum.

\section{Literature Review}

\subsection{Flipped Classroom}

The flipped classroom approach is a teaching strategy that transforms learning from instructor-oriented to student-oriented, as well as blended learning, combining traditional lecture-based learning with online learning [22,23]. The flipped classroom approach allows students to watch pre-recorded instructional videos before class according to their learning habits for self-directed and self-paced learning, and then participate in class discussions and complete assignments in the class [24]. A growing number of experimental studies related to the flipped classroom model have been conducted in different higher education subjects, such as English [25], medicine [26], physics [27], and chemistry [28]. The findings above indicated that students learn the knowledge and skills required for the production of teaching materials in the flipped classroom better than in the regular classroom. In a difficult task, the effects of the flipped classroom model were more observable [16].

In addition, the flipped classroom cannot achieve good results in all subject areas, and there are differences between disciplines [8], but previous studies have focused on mathematics, science, and health, among others. Rare studies extend to MET [8]. However, some articles found that there was no significant difference in students' learning achievement between the flipped classroom group and the control group [14,15,18-20]. The flipped classroom model also has some potential weaknesses. To enhance the learning, students need to watch the instructional video and finish the practice testing before or at the beginning of the lecture-based classroom. These students' preparation is likely producing a larger workload for students [29], and could even affect student satisfaction [30]. Thus, this study was used to test whether the flipped classroom model has more advantages than the lecture-centered instructional model. 


\subsection{Implementation of Flipped Classroom Among Pre-Service Teacher Students}

The flipped classroom environments can also be conducive to the learning, skills, and emotions of pre-service teacher students by creating a meaningful and realistic learning environment. González-Gómez et al. [31] evaluated the impact of conducting the flipped classroom in general science courses on the science self-efficacy and attitude of pre-service teacher students. The research results found that flipped classrooms had a significant impact on the science self-efficacy and attitude of the pre-service teacher students. Graziano [32] explored the benefits of the flipped classroom on pre-service teacher students in the curriculum of Language Acquisition and Learning. Cabi [15] conducted a quasi-experiment to evaluate the impact of flipped classroom model strategy on pre-service teacher students' English learning achievement. Choi and Lee [16] examined the impact of the flipped classroom approach on pre-service teacher students' learning performance and learning satisfaction in a technology integration course.

Graziano [32], Cabi [15], and Choi and Lee [16] indicated that the flipped classroom model has a positive effect on the student. The experimental research finding of Sun, $\mathrm{Hu}$, Wan, $\mathrm{Fu}$, and $\mathrm{Wu}[33]$ showed that flipped learning can promote the academic performance of students with different cognitive styles in the basic teacher courses of pre-service teacher students. Meanwhile, Sommer and Ritzhaupt [19] suggested that the flipped classroom instructional model does not have a significant impact on pre-service teacher students ${ }^{\prime}$ learning outcomes when the learning content is sufficiently complicated for them in an introductory technology literacy course. To sum up, in the study of pre-service teacher students' flipped classroom, there are some studies in English [15], language acquisition and learning [32], science [31], and other basic courses [33], but the investigation of pre-service teacher students in the course of MET is still unclear. Therefore, this study attempts to expand the influence of pre-service teacher students in the course of modern educational technology.

\subsection{Research Questions}

In the MET course, instillation teaching still exists, and it is difficult for inculcated students to play a main role in learning [4,32]. The flipped classroom is a student-oriented teaching method, which can break this phenomenon [5]. According to the achievement emotion model, the impacts of the flipped classroom on students' learning performance, learning satisfaction, learning motivation, learning outcomes, and self-efficacy have been investigated in various learning disciplines $[13,16,17,34-38]$. In line with this, the aim of the present study was to access the impact that the flipped classroom approach has on pre-service teacher students' learning performance in the MET course. It can shed light on the effectiveness of instruction for learners in the undergraduates' technology literacy course context. The following two research questions guided the conducting of this study.

1. To what extent does the flipped classroom affect learners' learning achievement compared with the regular classroom?

2. Does student participation in flipped classroom activities increase their learning satisfaction, learning motivation, and self-efficacy compared with the regular class3. Methods

\section{Methods}

\subsection{Participants}

The participants were 77 third-year undergraduates majoring in teacher education who enrolled in the MET course at a university in China during Fall 2019. Female students ( $n=49,64 \%$ ) outnumbered male students $(n=28,36 \%)$, which is common in the major of teacher education. These pre-service teacher students were mainly majoring in physical education $(n=34,44 \%)$, Chinese language and literature $(n=40,52 \%)$, history $(n=1,1 \%)$, and education $(n=2,3 \%)$. They took the MET course in preparation for their future career as teachers. The experimental group consisted of 41 students including 5 males and 36 females, who were instructed using the flipped classroom approach. As to the control 
group, it consisted of 36 students including 23 males and 13 females, who received the regular lecture-centered teaching. These two groups of students were instructed by the same instructor.

Participants were informed that they were participating in a quasi-experimental study, the data they provided were anonymous, and the study might be published. All the participants agreed to participate in the study in their course.

\subsection{Measurement}

To cope with the research questions mentioned above, an experiment was designed and implemented to assess the learning effects, including learning achievement, learning satisfaction, learning motivation, and self-efficacy. This study used a variety of data collection tools to try to echo the research questions. The measuring tools utilized in the research mainly include a pre-test and post-test; practice assignment and transfer assignment; and the questionnaires of learning satisfaction, learning motivation, and self-efficacy.

The pre-test aimed to evaluate a baseline score from each student and to check the equivalence of prior knowledge of Photoshop between the two groups at the beginning [39]. On one hand, it was useful to consider learner achievement. On the other hand, it was useful for researchers to exclude initial differences in the description of the results [39]. The pre-test included ten-item single-choice questions developed by the instructor and research team according to the learning objectives for the Photoshop learning that followed. The items of the post-test were the same as those of the pre-test questions, but the questions and the single-choice answers were presented in a different order.

The practice assignments, which are Photoshop works completed by the students for each topic, help the researchers to examine how well the students perform with the skills they have learned in the classroom under the two teaching methods. The Photoshop assignments submitted by students are in the format of PSD. Students' works are mainly evaluated for accuracy, completeness, and aesthetics.

Transfer of learning will happen when learners acquire skills, knowledge, and attitudes and then use those abilities in different situations [40]. The "transfer assignment" was used to gather scores to examine the students' capability to transfer those skills to an aspect or theme related to their field of study or interest, while the "practice assignment" was detailed in directions and provided students with specified requirements and instructions about exactly what they need to do. In this study, the criteria used to evaluate students' transfer assignment referred to the research of Sommer and Ritzhaupt [19]. Sommer and Ritzhaupt took the knowledge points previously learned by students as the evaluation standard of the transfer assignment, evaluated the students' Photoshop transfer assignment, and informed the students of the rules of the assignment evaluation when the assignment was published [19], resulting in a rubric covering the key operation points of the four modules to assess students' transfer assignments. The knowledge points of a module are 25 points and the total points of the four modules are 100 points.

The questionnaire of learning satisfaction, learning motivation, and self-efficacy was taken from the previous measurements designed by several researchers [41-44]. The learning satisfaction, learning motivations, and self-efficacy questionnaire consist of four, six, and eight items, respectively. These items were all assessed on five-point Likert scales. As the participants in this study were non-native English speakers, all authors translated and reviewed the questionnaire. Then, two experts in the field of educational technology examined the validity of the questionnaires. To ensure all items demonstrated good clarity of Chinese, three volunteer college students responded to the items in a questionnaire and gave feedback about how they perceived and understood each item. To ensure the reliability of the questionnaire, this study referred to the method used by Lin et al. [45], that is, the Cronbach's alpha coefficient was used to evaluate the internal consistency of the questionnaire. The results show that the Cronbach's alpha values of learning satisfaction, 
learning motivations, and self-efficacy questionnaire were $0.91,0.86$, and 0.93 , respectively. Therefore, the questionnaire has acceptable reliability.

\subsection{Design of Instructional Approaches}

\subsubsection{Selection of Instructional Content}

The MET course required all pre-service teacher students to be taught over 18 weeks for three credit hours every week as a three-credit course. The MET course aims to develop and improve pre-service teacher students' technical literacy, which is the ability to understand and apply technological tools [19], and to develop teacher students' capacity to integrate information technology into the curriculum. In the MET course, students are taught how to use software such as Adobe Photoshop, Camtasia studio, and PowerPoint, among others. In the MET course, the first four modules mainly teach the conceptual knowledge of educational technology, while the four modules mainly focus on procedural knowledge, such as the operation skills of Photoshop, Camtasia studio, Audacity, and so on. The flipped classroom has different effects on students in terms of procedural and conceptual problems [46]. Combined with the content of the MET course, Module 5 was chosen to conduct this experiment. In Module 5, students will be introduced to some of the basic concepts of Photoshop and practice how to generate specific images by manipulating the tools in Photoshop under the instructor's step-by-step instruction. The aim of Module 5 was for students to develop the necessary skills to use Photoshop to edit images in future course modules and, eventually, they will be able to use these skills in their future professional careers.

The control group of MET instruction included the instructor introducing the interface and tools of Photoshop, then the students engaged in one specific practice assignment as coursework on their own. The experimental group watched a recorded short video asynchronously before the control group. The students then participated in the practice assignment during the face-to-face class, with the students solving the problems, offering support as needed, and encouraging collaboration. However, the syllabus, textbook, assignments, and exams of the two treatments were similar.

\subsubsection{Before-Class Activities}

In the flipped treatments, the students were instructed through videos. Therefore, the instructor would use Camtasia studio 9 to record instructional videos that only recorded the screen and the teacher's voice for the Photoshop module every week. The average duration of which was no more than 10 minutes. Many students usually log in and browse their social networking websites or mobile instant messaging applications every day instead of logging in the course website [6]. Therefore, this study used QQ, one of the most popular instant messaging social softwares in China, as a platform for teachers to communicate with learners in the experimental group before class. Before the beginning of the course, the instructor or teaching assistant uploaded the instructional video and document to the learning space of the QQ group, in which both the instructor and the learners could interact, resolving any doubts or questions, publishing notices, and sharing additional resources. Learners in the flipped treatment were allowed five days to watch and summarize the video or document learning materials independently at their convenience. The QQ group displays the number of times the video or document has been downloaded, which allows the instructor to monitor whether all students download the video before class. Because some students may not watch the instructional video or document, the learning process is also very difficult to control. Thus, to provide an effective link between out-of-class and in-class activities, the learners were asked to report their doubts and questions about the present section in the QQ group after finishing the learning tasks (Figure 1). 


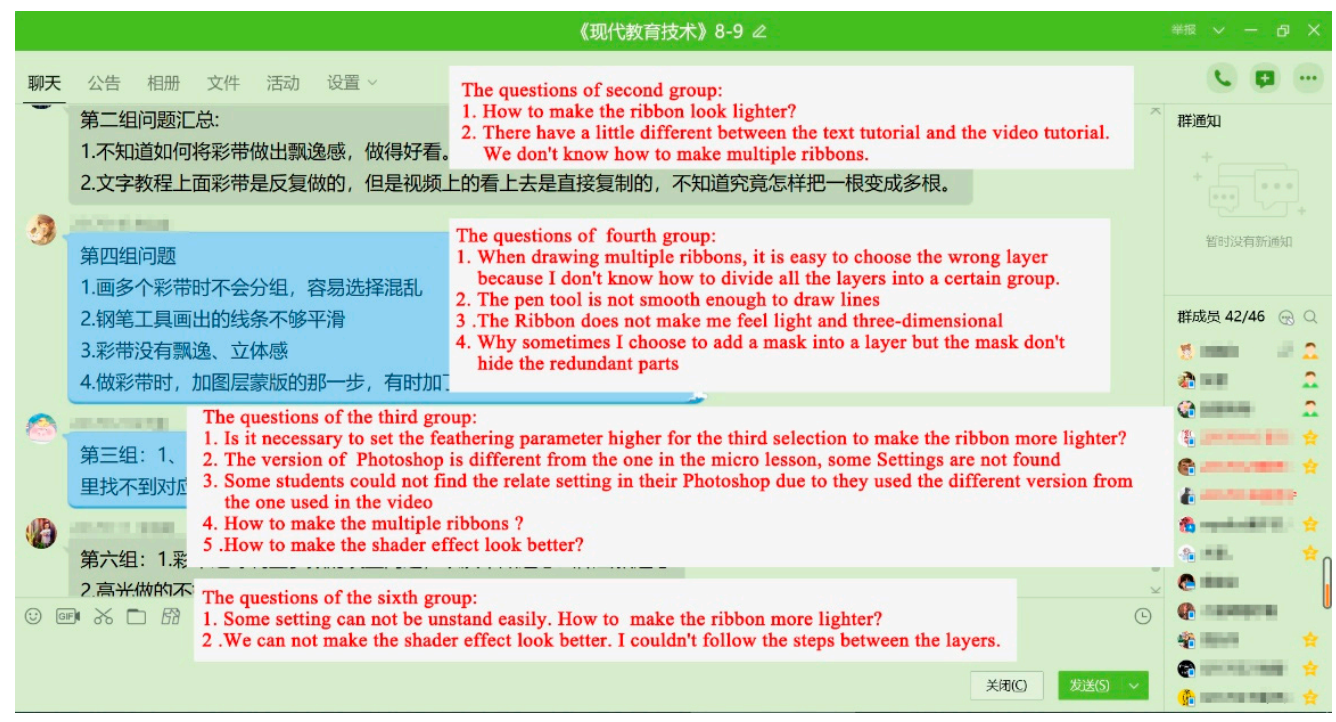

Figure 1. Snapshot of the QQ group.

\subsubsection{In-Class and After-Class Activities}

In the traditional approach, learners were instructed by listening to the presentations. They will follow the instructors' step-by-step instruction of the coursework. They can also ask some questions if they cannot follow the steps or have any questions. Then, they finished the coursework in the recess time of the in-class time. Regarding the flipped classroom, the instructor mainly focused on the students' main doubts and problems based on the feedback that she had received before class. Then, the students continued to complete the required coursework in class.

After class, students of the control group finished the coursework they learned in the class. They followed the steps presented by the instructor. The experiment group redesigned or revised the coursework following the instructions they received from the in-class activities.

\subsection{Procedure}

Before conducting the experiment, the researchers informed all participants of the aim and design of the research in the course and obtained consent from the students from two groups. During the experiment, the personal information of all the participants was hidden.

The experimental implementation process of this study is represented in Figure 2. All the participants from the experimental and regular groups finished a pre-test and the pre-questionnaire at the beginning of the first week of the experiment. The pre-test was to test participants' previous subject knowledge. The pre-questionnaire was to collect the participants' demographic background, learning satisfaction, learning motivation, and self-efficacy. To ensure the recovery rate of the questionnaire, the instructor gave students enough time to complete the questionnaire in class. Still, to maintain a valid comparison, only those who completed both the pre-questionnaire and post-questionnaire and all practices for this study were used in the analysis. As a result, no significant differences were found between the two groups in terms of the factors of participants' learning satisfaction, learning motivation, self-efficacy, and prior subject area knowledge. Thus, the above factors were well controlled before the implementation of the experiment in this research. 


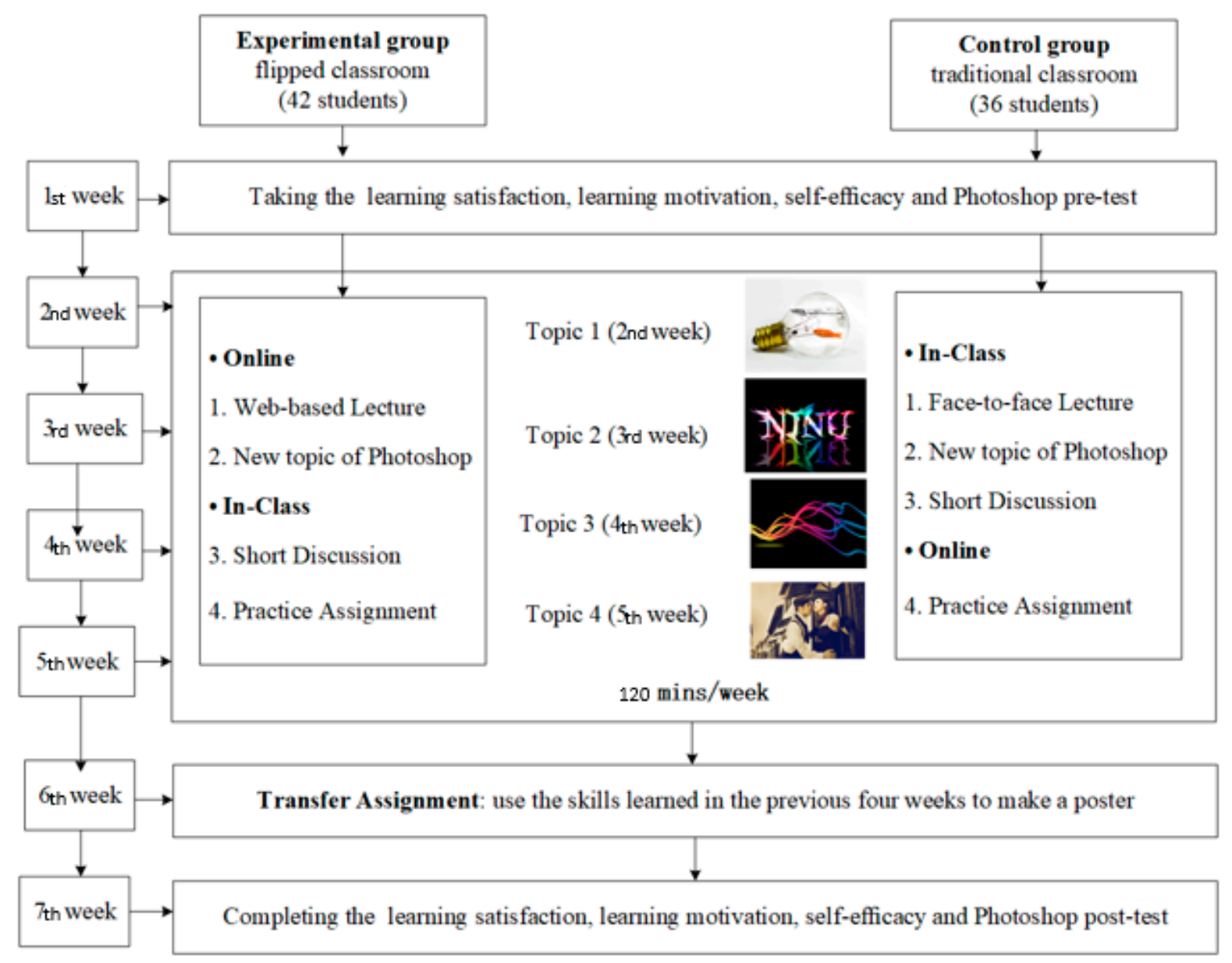

Figure 2. Diagram of the experiment design.

\subsection{Data Analysis}

SPSS version 20.0 was used to calculate the performances of the two groups, including their pre-tests and post-tests, pre-questionnaires and post-questionnaires, and the score of practice and transfer assignment. This study employed the independent sample $t$-test, analysis of covariance (ANCOVA), and analysis of variance (ANOVA) models to compare the mean response between the treatment group and the control group in terms of learning achievement, learning satisfaction, self-efficacy, and learning motivation quantitative data [47]. The independent sample $t$-test was used to analyze the learning achievement data from the Photoshop pre-test/post-test of the control group and experimental group. A one-way ANCOVA was run on the data from the learning satisfaction, learning motivation, and self-efficacy survey, while ANOVAs were conducted for the score of practice assignments and transfer assignments. It is important to test the homogeneity of the two groups of data to ensure that the statistical results are reliable; therefore, in this study, the Levene's test for equality of variances was conducted to test if homogeneity of variance was equal across the control and experimental groups [48]. Partial Eta-squared $\left(\eta^{2}\right)$ cited as a measure of effect size was used in the educational research to evaluate the strength of the relationship between the independent variables and dependent variables [49,50], and Partial Eta-squared can be benchmarked against Cohen's criteria of small effect (0.2), medium effect (0.5), and large effect (0.8) [51]. 


\section{Results}

\subsection{Analysis of Learning Achievement \\ 4.1.1. Pre-Test/Post-Test}

This study explored the impact of the flipped classroom strategy on the students' mastery of Photoshop knowledge. The independent sample $t$-tests were employed to analyze the pre- and post-tests of control group and experimental group. The pre-test and post-test used the identical assessment for data collection and analysis, but the order of questions and single-choice answers was different. Then, these responses from the pre-test and post-test were coded as true (1) or false (0). The maximum amount of points that could be achieved on the pre-test and post-test was six and ten, respectively. The skewness of the pre-test and post-test data is -0.477 and 0.117 , respectively, and the kurtosis is -0.018 and -0.892 , respectively, so there is no severe deviation from normality. As depicted in Table 1, the independent sample $t$-test results showed that no satisfied significance $(t=-2.52, p=0.14>0.05)$ was found in the Photoshop pre-test between the control group and experimental group, indicating the students of the two groups had the same basic knowledge of Photoshop before the experiment. The Photoshop post-tests of the two groups with $t=-0.45(p=0.000<0.001)$ showed that a satisfactory significant difference was found between students' achievements with different teaching methods. Cohen's $d$ is an effect size indicator commonly used for an independent sample $t$-test, including the small effect (0.2), medium effect (0.5), and large effect (0.8) [52]. The Cohen's $d$ result of the post-test is $\mid-2.17 \mathrm{I}$, that is, $2.17>0.8$. Thus, it is large effect size, indicating that the flipped classroom teaching mode has a great impact on students' mastery of Photoshop knowledge.

Table 1. The independent sample $t$-test on students' achievements with different groups.

\begin{tabular}{ccccccc}
\hline Variable & Group & N & M & SD & $t$ & $p$ \\
\hline \multirow{2}{*}{ Pre-test } & CG & 36 & 3.72 & 1.16 & -2.52 & 0.140 \\
& EG & 41 & 4.32 & 0.91 & & \\
Post-test & CG & 36 & 4.36 & 1.18 & -0.45 & 0.000 \\
& EG & 41 & 7.24 & 1.46 & & \\
\hline
\end{tabular}

Note. CG represents the control group and EG represents the experimental group.

\subsubsection{Practice Assignment}

This study explored the impact of the flipped classroom model on the score of the practice assignments of learners. One-way ANOVA was employed using the two instructional approaches as independent variables, while the score of the practice assignments was a dependent variable. Researchers collected and analyzed the graded score from four weeks' practice assignments, allowing students to create images using Photoshop software in specific directions.

After verifying that the assumption of homogeneity of the regression coefficients within the groups was not violated (Topic $1: \mathrm{F}=1.19, p>0.05$; Topic 2: $\mathrm{F}=7.78, p>0.05$; Topic 3: $\mathrm{F}=0.23, p>0.05$; Topic $4: \mathrm{F}=2.03, p>0.05$ ), the score of the practice assignments was analyzed with the one-way ANOVA. For the four topics, there is no severe deviation from normality, and the skewness is 0.084 (Topic 1), -0.474 (Topic 2), 0.341 (Topic 3), and -0.153 (Topic 4 ), and the kurtosis is -0.789 (Topic 1 ), -0.373 (Topic 2), -1.003 (Topic 3 ), and -1.461 (Topic 4). The result is shown in Table 2. Regarding Topic 1, the average score of the practice assignment for flipped classroom students (90.10 \pm 0.44$)$ was $3.153(95 \%$ confidence interval (CI): 1.88 4.42), exceeding that of the control group students (86.94 \pm $0.47)$, showing a statistically significant difference $\left(\mathrm{F}=24.41, p<0.001\right.$, partial $\left.\eta^{2}=0.25\right)$. Regarding Topic 2, the average score of practice assignment for students in the flipped classroom group (91.88 \pm 2.47 ) was 4.24 (95\% CI: $2.73 \sim 5.75)$, surpassing that of students in the control group $(87.64 \pm 4.09)$, and the difference was statistically significant $(\mathrm{F}=29.51$, $p<0.001$, partial $\eta^{2}=0.29$ ). Regarding Topic 3, the average score of practice assignments for students in the flipped classroom (90.76 \pm 3.14 ) was 5.26 (95\% CI: 3.61 6.90), higher 
than that of students in the control group $(85.50 \pm 4.10)$, and the difference was statistically significant $\left(\mathrm{F}=40.42, p<0.001\right.$, partial $\left.\eta^{2}=0.35\right)$. Regarding Topic 4 , the average score of practice assignments for students in the flipped classroom group (93.20 \pm 0.54$)$ was 8.084 (95\% CI: 6.50 9.67), higher than that of students in the control group (85.11 \pm 0.58$)$, and the difference was statistically significant $\left(\mathrm{F}=103.47, p<0.001\right.$, partial $\left.\eta^{2}=0.58\right)$.

Table 2. One-way analysis of variance (ANOVA) result of the practice assignment of the different groups.

\begin{tabular}{ccccccc}
\hline Source & Group & $\mathbf{N}$ & $\mathbf{M}$ & SD & $\mathbf{F}$ & Partial $\eta^{2}$ \\
\hline \multirow{2}{*}{ Topic 1} & CG & 36 & 86.94 & 2.43 & $24.41^{* * *}$ & 0.25 \\
& EG & 41 & 90.10 & 3.08 & & \\
Topic 2 & CG & 36 & 87.64 & 4.09 & $29.51^{* * *}$ & 0.29 \\
& EG & 41 & 91.88 & 2.47 & & \\
Topic 3 & CG & 36 & 85.50 & 4.10 & $40.42^{* * *}$ & 0.35 \\
& EG & 41 & 90.76 & 3.14 & & \multirow{2}{*}{0.58} \\
Topic 4 & CG & 36 & 85.11 & 3.94 & $103.47^{* * *}$ & \\
& EG & 41 & 93.20 & 3.02 & & \\
\hline
\end{tabular}

Note. ${ }^{* * *} p<0.001$. CG represents the control group and EG represents the experimental group.

\subsubsection{Transfer Assignment}

Two groups of students creatively used the knowledge they acquired from instruction and practiced in an open-ended assignment. This assessment examined students' performance on the transfer task and further explored whether there was a correlation between grades and teaching methods. One-way ANOVA was employed using the two instructional approaches as independent variables, while the score of the transfer assignment was a dependent variable. The assumption of homogeneity was met, indicated by Levene's test of equality of error variances at $\mathrm{F}(1,75)=0.06, p=0.81$. The skewness of the transfer assignment data is 0.117 and the kurtosis is -0.977 , so there is no severe deviation from normality. The descriptive statistics for this assignment are shown in Table 3. For this transfer assignment, the difference between the control group and experimental group was statistically significant at $\mathrm{F}=39.78, p<0.001$, partial $\eta^{2}=0.35$.

Table 3. One-way ANOVA result of transfer assignment of the two groups.

\begin{tabular}{ccccccc}
\hline Group & $\mathbf{N}$ & $\mathbf{M}$ & SD & F & Sig & Partial $\eta^{2}$ \\
\hline $\begin{array}{c}\text { control } \\
\text { group } \\
\text { experimental }\end{array}$ & 36 & 87.19 & 3.54 & 39.78 & 0.000 & 0.35 \\
$\quad 41$ & 92.05 & 3.22 & & & \\
group & & & & & & \\
\hline
\end{tabular}

\subsection{Analysis of Learning Satisfaction, Motivation, and Self-Efficacy}

This study aims to explore whether the flipped classroom would result in enhancing the learning satisfaction, motivation, and self-efficacy of students during the learning process. Table 4 depicts the results regarding students' learning satisfaction, learning motivation, and self-efficacy between the control group and experimental group.

In the experimental group, the mean (M) and standard deviation (SD) of the three dimensions of the pre-questionnaire, namely, learning satisfaction, learning motivation, and self-efficacy, were 15.32 and 2.57, 14.61 and 2.70, and 22.56 and 3.83, respectively. For the control group, they were 15.67 and 2.28, 15.44 and 2.42, and 23.36 and 3.11, respectively. The $t$-test results showed that there was no significant difference in the learning satisfaction $(t=0.63, p>0.05)$, learning motivation $(t=1.42, p>0.05)$, or self-efficacy $(t=0.998, p>0.05)$ of the two groups, indicating that the experimental group of students had the same level of learning satisfaction, learning motivation, and self-efficacy as the control group before the experiment. For the learning satisfaction, learning motivation, and self-efficacy, there is no severe deviation from normality; the skewness is $-0.370,0.754$, and 0.273 , and the kurtosis is $1.648,0.069$, and -0.258 , respectively. 
Table 4. One-way ANCOVA result of the post-questionnaire of the two groups.

\begin{tabular}{ccccccccc}
\hline Variable & Group & N & M & SD & $\begin{array}{c}\text { Adjusted } \\
\text { Mean }\end{array}$ & SE & F & $\begin{array}{c}\text { Partial } \\
\eta^{2}\end{array}$ \\
\hline $\begin{array}{l}\text { Learning } \\
\text { satisfac- }\end{array}$ & CG & 36 & 14.72 & 3.46 & 14.63 & 0.46 & $\begin{array}{c}13.74 \\
* * *\end{array}$ & 0.16 \\
$\begin{array}{c}\text { tion } \\
\text { mearning }\end{array}$ & EG & 41 & 15.29 & 2.45 & 15.37 & 0.43 & & \\
$\begin{array}{c}\text { motiva- } \\
\text { tion }\end{array}$ & EG & 46 & 22.08 & 3.75 & 21.93 & 0.56 & $10.74 *$ & 0.13 \\
$\begin{array}{c}\text { Self- } \\
\text { efficacy }\end{array}$ & CG & 36 & 15.58 & 2.96 & 14.30 & 0.42 & $\begin{array}{c}18.15 \\
* * *\end{array}$ & 0.20 \\
\hline Note. ${ }^{* * *} p<0.001 ;{ }^{*} p<0.05$. CG represents the control group and EG represents the experimental group.
\end{tabular}

A one-way ANCOVA analysis was performed and the results are presented in Table 4. It was found that the scores of learning satisfaction of students in the experimental group were significantly higher than those in the control group $\left(\mathrm{F}=13.74, p<0.001, \eta^{2}=0.16\right)$. For learning motivation, the scores of learning motivation of students in the experimental group were also better than those in the control group $\left(\mathrm{F}=10.74, p<0.05, \eta^{2}=0.13\right)$. In addition, the students in the experimental group gained a significantly higher score for selfefficacy than the students in control group $\left(\mathrm{F}=32.24, p<0.001, \eta^{2}=0.40\right)$. According to the criteria of partial $\eta^{2}$, the students' learning satisfaction/learning motivation/self-efficacy was largely associated with the instructional strategy.

\section{Discussion and Conclusions}

Based on the achievement emotion model, the present study explored what benefit the flipped classroom might have for pre-service students taking the MET course. Both the students' learning achievement and perception data regarding learning satisfaction, learning motivation, and self-efficacy were used to evaluate these instructional approaches. The current study tries to answer the following cognitive and affective learning questions: (1) the effect of the flipped classroom model on students' learning achievement in MET course; (2) the impact of the flipped classroom model on students' learning satisfaction, learning motivation, and self-efficacy in the MET course.

5.1. To What Extent Does the Flipped Classroom Affect Learners' Learning Achievement Compared with the Regular Classroom?

The results indicated that the students who experienced flipped classroom performed better than the students who experienced regular class. As for the aspect of learning achievement, four practice assignments, a transfer assignment, and the post-test were used to collect data and assess the impact of the flipped classroom. After the data analysis, it was found that students who received flipped classrooms gained significantly higher scores in the pre-test, post-test, assignment practices, and transfer assignment than the control group. With the increasing difficulty of learning content weekly, the gap between the experimental group and the control class in the average score of the practice assignment was gradually increasing, as shown in Table 2.

Learning instructional videos and materials before class helped students to enhance learning and understanding of the key knowledge. Additionally, different forms of learning materials were provided to meet students' needs and learning preferences [53]. Regarding digital learning, to some extent, students communicated with each other through the QQ group to solve some doubts, which could encourage and promote their participation in learning [13]. However, prior studies $[13,37]$ indicated that the flipped classroom approach has potential benefits on students' learning achievement and satisfaction [15]. The flipped classroom teaching model does not have a significant impact on learners' learning outcomes when the learning content is not complicated enough for undergraduates [19]. In contrast to the above results, this study suggested that, regarding the control value model, the learning achievement of the experimental group performed better than the control group. 
In the research of Sommer and Ritzhaupt [19], students in the flipped class and traditional class also learned Photoshop in the undergraduate technology literacy course, but there was no significant difference in the learning achievement. Sommer and Ritzhaupt attributed this phenomenon to the simplicity of the Photoshop operation and the lack of continuity between its content and its knowledge. In this study, the contents of the four learning topics have continuity in knowledge content. As the learning progresses, the task becomes more difficult. In the first topic, students need to learn how to add a mask to the picture; while in the second topic, students need to learn stroke and effect settings between layers; in the third topic, students need to learn how to use the pen tool and the use of curves; and in the fourth topic, students need to use the mask tool, effect settings between layers, and operation of curves to finish the practice assignment. In the transfer assignment, students need to use the Photoshop skills learned in the previous four topics. Therefore, in the MET course, the flipped classroom teaching method can help students to achieve better learning achievements compared with the traditional teaching method.

\subsection{Does Student Participation in Flipped Classroom Activities Increase Their Learning Satisfaction, Learning Motivation, and Self-Efficacy Compared with the Regular Classroom?}

The results indicated that students experienced the flipped classroom performed better than students experienced regular class. As for the aspect of learning achievement, four practice assignments, a transfer assignment, and the post-test were used to collect data and assess the impact of the flipped classroom. After the data analysis, it was found that students who took part in the flipped classroom had significantly higher scores in the pre-test and post-test, assignment practices, and transfer assignment than the control group. With the increasing difficulty of learning content weekly, the gap between the experimental group and the control class in the average score of the practice assignment was gradually widening (Table 2).

In terms of learning satisfaction, learning motivation, and self-efficacy, the result indicated that a significant statistical difference was found between the flipped classroom and lecture-centered approaches for participants' evaluation of the class. These findings can be seen in previous studies $[13,35,36,41,54,55]$. It is a common way in the MET for the instructor to control students' computers to demonstrate specific steps of examples, and students then operate on their computers. However, this teaching strategy may have some drawbacks. Students in the lecture-centered classroom found it difficult to keep up with the instructor's instructions, especially encountering some complicated skills of Photoshop. On the contrary, students in the flipped classroom could watch the instructional video or document before the face-to-face lecture repeatedly, and they already have a preliminary understanding of the complex Photoshop operations before the class. In the QQ group of the classes taking part in the flipped classroom approach, many students would seek help from the QQ groups. The instructor responded to some operational questions raised by students before class, and some students who had mastered the learning content would also help the students with problems and even shared additional online resources to supplement.

Under the flipped classroom approach, students could practice the skills of Photoshop at any place and any time they preferred and felt it convenient. This great convenience undoubtedly makes them satisfied [56]. In addition, as students know that the instructor will monitor their learning status through feedback and interaction with each other on social media, students feel pressure from their peers that eventually promotes their active learning and engagement [29]. On the other hand, the difficulty of the knowledge is increasing every week, and those knowledge points also have some connection (such as layer masks, layer style, and so on). Therefore, if a student in the lecture-centered classroom does not listen carefully in one lesson, it is hard to keep up with the step of the instructor. Besides, reinforcement learning with Photoshop might make students feel frustrated and cause dissatisfaction [57]; these bad emotions have further affected students' learning emotions and achievement. Supporting those studies and analyzing via the achievement emotion model, the present evidence suggests that the participants 
self-efficacy, learning motivation, and satisfaction were higher than those participants from the control group, while the flipped approach is more effective than the lecture-centered approach for delivering the MET class.

\subsection{Implication}

Blended learning strategies offer many options for higher educators. The current study provides insights into the flipped classroom model in the effect of learners' academic performance, learning satisfaction, learning motivation, and self-efficacy in the context of the MET course for pre-service teacher students. The result indicated that the flipped classroom model had a significant effect on the student, which was more visible in the difficult and complicated knowledge and skills. This study lends further support to the relational perspectives of Choi and Lee [16] that the flipped classroom approach was more effective for students to learn knowledge and skills than the regular classroom. However, prior researchers suggested that the flipped classroom might not improve students' academic performance when the learning content was not complicated enough for learners $[16,19]$. Moreover, some learners were not willing to accept the new teaching method, or are even dissatisfied, because the flipped classroom approach required higher self-regulated learning of students $[19,58]$. When educators want to choose the flipped classroom approach, it is important to consider whether the flipped classroom teaching method is suitable for the instructional content.

\subsection{Limitations and Future Works}

Although the results show that the flipped classroom model has a positive effect on students' learning outcomes compared with the control group, this study has some limitations, which have been mentioned in some similar experiments $[4,19,59,60]$. Firstly, the duration of the intervention is short (one month). Secondly, the present study is limited in scope to pre-service teacher students and the sample size of students in the two groups was small-scale, thus the generalizability of the results of this work must be carefully approached. This limitation calls for more longitudinal studies in the future, including larger sample sizes and wider periods of the survey for the consideration of the current pilot study. Thirdly, because of the complexity of the learning environment, there might be some potential factors affecting the students' learning outcomes and some perceptions. More data, such as the learning behavior [61] and emotions [62,63] before class and in class, might be collected for further analysis. Finally, the flipped classroom teaching model is not the only way to promote pre-service teacher students' learning in MET courses. In the future, other different learning models can be compared with the flipped classroom teaching model.

Author Contributions: Conceptualization, L.Z.; methodology, X.L.; writing-original draft preparation, L.Z. and X.L.; writing - review and editing, Y.-S.S. All authors have read and agreed to the published version of the manuscript.

Funding: This study was funded by National Social Science Foundation of China, grant number BCA200093, and Priority Academic Program Development of Jiangsu Higher Education Institutions. Moreover, this study was supported by the Ministry of Science and Technology, Taiwan, under grant MOST 109-2511-H-019-004-MY2 and MOST 109-2511-H-019-001.

Institutional Review Board Statement: Not applicable.

Informed Consent Statement: Informed consent was obtained from all subjects involved in the study.

Data Availability Statement: Not applicable.

Acknowledgments: We would like to acknowledge all the people who have helped us with this study. We are grateful for their contribution.

Conflicts of Interest: The authors declare no conflict of interest. 


\section{References}

1. Gudmundsdottir, G.B.; Hatlevik, O.E. Newly qualified teachers' professional digital competence: Implications for teacher education. Eur. J. Teach. Educ. 2018, 41, 214-231. [CrossRef]

2. Krueger, K.; Hansen, L.; Smaldino, S. Preservice teacher technology competencies. TechTrends 2000, 44, 47-50. [CrossRef]

3. Pettersson, F. On the issues of digital competence in educational context-a review of literature. Educ. Inf. Technol. 2017, 23, 1005-1021.

4. Wang, Y.; Zhao, C.; Zhao, R. The impact of modern educational technology on college teaching and its application strategies. Adv. Intell. Syst. Comput. 2019, 929, 999-1006.

5. Liu, M. The application of a flipped classroom model in modern educational technology. Eng. Educ. Life Long Learn. 2017, 27, 57-71. [CrossRef]

6. Chyr, W.-L.; Shen, P.-D.; Chiang, Y.-C.; Lin, J.-B.; Tsia, C.-W. Exploring the Effects of Online Academic Help-Seeking and Flipped Learning on Improving Students' Learning. Educ. Technol. Soc. 2017, 20, 11-23.

7. Tondeur, J.; van Braak, J.; Siddiq, F.; Scherer, R. Time for a new approach to prepare future teachers for educational technology use: Its meaning and measurement. Comput. Educ. 2016, 94, 134-150. [CrossRef]

8. Cheng, L.; Ritzhaupt, A.D.; Antonenko, P. Effects of the flipped classroom instructional strategy on students' learning outcomes: A meta-analysis. Educ. Tech. Res. Dev. 2019, 67, 793-824. [CrossRef]

9. Moreno, R.; Mayer, R. Interactive multimodal learning environments: Special issue on interactive learning environments: Contemporary issues and trends. Educ. Psychol. Rev. 2007, 19, 309-326. [CrossRef]

10. Pekrun, R. The control-value theory of achievement emotions: Assumptions, corollaries, and implications for educational research and practice. Educ. Psychol. Rev. 2006, 18, 315-341. [CrossRef]

11. Hascher, T.; Hagenauer, G. Openness to theory and its importance for pre-service teachers' self-efficacy, emotions, and classroom behaviour in the teaching practicum. Int. J. Educ. Res. 2016, 77, 15-25. [CrossRef]

12. Pekrun, R.; Perry, R.P. Control-value theory of achievement emotions. In International Handbook of Emotions in Education; Pekrun, R., Linnenbrink-Garcia, L., Eds.; Routledge: New York, NY, USA, 2014; pp. 120-141.

13. Alamri, M.M. Students' learning achievement performance and satisfaction in a flipped classroom in Saudi Arabia. Technol. Enhanc. Learn. 2019, 11, 103-119. [CrossRef]

14. Burnham, K.D.; Mascenik, J. Comparison of student performance and perceptions of a traditional lecture course versus an inverted classroom format for clinical microbiology. J. Chiropr. Educ. 2018, 32, 90-97. [CrossRef]

15. Cabi, E. The impact of the flipped classroom model on students' learning achievement. Int. Rev. Res. Open Dis. 2018, 19, 202-221. [CrossRef]

16. Choi, J.; Lee, Y. To what extent does 'flipping' make lessons effective in a multimedia production class? Innov. Educ. Teach. Int. 2018, 55, 3-12. [CrossRef]

17. Jdaitawi, M. The effect of flipped classroom strategy on students learning outcomes. Int. J. Instr. 2019, 12, 665-680. [CrossRef]

18. Smallhorn, M. The flipped classroom: A learning model to increase student engagement not academic achievement. Stud. Success 2017, 8, 43-53. [CrossRef]

19. Sommer, M.; Ritzhaupt, A. Impact of the flipped classroom on learner achievement and satisfaction in an undergraduate technology literacy course. J. Inf. Technol. Educ. Res. 2018, 17, 159-182. [CrossRef]

20. Tse, W.S.; Choi, L.Y.A.; Tang, W.S. Effects of video-based flipped class instruction on subject reading motivation. Br. J. Educ. Technol. 2017, 50, 385-398. [CrossRef]

21. Hao, Y.; Lee, K.S. Teaching in flipped classrooms: Exploring pre-service teachers' concerns. Comput. Hum. Behav. 2016, 57, 250-260. [CrossRef]

22. Park, S.E.; Howell, T.H. Implementation of a flipped classroom educational model in a predoctoral dental course. J. Dent. Educ. 2015, 79, 563-570. [CrossRef]

23. Williams, D.E. The future of medical education: Flipping the classroom and education technology. Ochsner J. 2016, 16, 14-15. [PubMed]

24. Zhang, X.M.; Yu, J.Y.; Yang, Y.; Feng, C.P.; Lyu, J.; Xu, S.L. A flipped classroom method based on a small private online course in physiology. Adv. Physiol. Educ. 2019, 43, 345-349. [CrossRef]

25. Lin, C.J.; Hwang, G.J. A learning analytics approach to investigating factors affecting EFL students' oral performance in a flipped classroom. Educ. Technol. Soc. 2018, 21, 205-219.

26. Day, L.J. A gross anatomy flipped classroom effects performance, retention, and higher-level thinking in lower performing students: Flipped anatomy effects lower performing students. Anat. Sci. Educ. 2018, 11, 565-574. [CrossRef] [PubMed]

27. Stohr, C.; Demaziere, C.; Adawi, T. The polarizing effect of the online flipped classroom. Comput. Educ. 2020, 147, 103789. [CrossRef]

28. Fautch, J.M. The flipped classroom for teaching organic chemistry in small classes: Is it effective? Chem. Educ. Res. Pract. 2015, 16, 179-186. [CrossRef]

29. Huang, H.L.; Chou, C.P.; Leu, S.; You, H.L.; Chen, C.H. Effects of a quasi-experimental study of using flipped classroom approach to teach evidence-based medicine to medical technology students. BMC Med. Educ. 2020, 20, 31. [CrossRef] [PubMed]

30. Centra, J.A. Will teachers receive higher student evaluations by giving higher grades and less course work? Res. High. Educ. 2003, 44, 495-518. [CrossRef] 
31. González-Gómez, D.; Jeong, J.S.; Cañada, F.C. Enhancing science self-efficacy and attitudes of pre-service teacher (PST) through a flipped classroom learning environment. Interact. Learn. Environ. 2019, 6. [CrossRef]

32. Graziano, K.J. Peer teaching in a flipped teacher education classroom. TechTrends 2017, 61, 121129. [CrossRef]

33. Sun, F.R.; Hu, H.Z.; Wan, R.G.; Fu, X.; Wu, S.J. A learning analytics approach to investigating pre-service teachers' change of concept of engagement in the flipped classroom. Interact. Learn. Environ. 2019, 5, 1-17. [CrossRef]

34. Lag, T.; Saele, R.G. Does the flipped classroom improve student learning and satisfaction? A systematic review and meta-analysis. AERA Open 2019, 5, 1-17. [CrossRef]

35. Bouwmeester, R.A.M.; De Kleijn, R.A.M.; Van Rijen, H.V.M.; Westerveld, H.E. Flipping the medical classroom: Effect on workload, interactivity, motivation and retention of knowledge. Comput. Educ. 2019, 139, 118-128. [CrossRef]

36. Chuang, H.H.; Weng, C.Y.; Chen, C.H. Which students benefit most from a flipped classroom approach to language learning. Br. J. Educ. Technol. 2018, 49, 56-68. [CrossRef]

37. Kazanidis, I.; Pellas, N.; Fotaris, P.; Tsinakos, A. Can the flipped classroom model improve students' academic performance and training satisfaction in Higher Education instructional media design courses? Br. J. Educ. Technol. 2019, 50, 2014-2027. [CrossRef]

38. Rodriguez, G.; Diez, J.; Perez, N.; Banos, J.E.; Carrio, M. Flipped classroom: Fostering creative skills in undergraduate students of health sciences. Think. Ski. Creat. 2019, 33, 100575. [CrossRef]

39. Gribbons, B.; Herman, J. True and Quasi-Experimental Designs; ERIC Clearinghouse on Assessment and Evaluation: Washington, DC, USA, 1997; pp. 1-7.

40. Ford, J.K.; Smith, E.M.; Weissbein, D.A.; Gully, S.M.; Salas, E. Relationships of goal orientation, metacognitive activity, and practice strategies with learning outcomes and transfer. J. Appl. Psychol. 1998, 83, 218-233. [CrossRef]

41. Sergis, S.; Sampson, D.G.; Pelliccione, L. Investigating the impact of flipped classroom on students' learning experiences: A self-determination theory approach. Comput. Hum. Behav. 2018, 78, 368-378. [CrossRef]

42. Cho, M.H.; Park, S.W.; Lee, S. Student characteristics and learning and teaching factors predicting affective and motivational outcomes in flipped college classrooms. Stud. High. Educ. 2019, 46, 509-522. [CrossRef]

43. Wang, L.C.; Chen, M.P. The effects of game strategy and preference-matching on flow experience and programming performance in game-based learning. Innov. Educ. Teach. Int. 2010, 47, 39-52. [CrossRef]

44. Hwang, G.J.; Yang, L.H.; Wang, S.Y. A concept map-embedded educational computer game for improving students' learning performance in natural science courses. Comput. Educ. 2013, 69, 121-130. [CrossRef]

45. Lin, Y.N.; Hsia, L.H.; Hwang, G.J. Promoting pre-class guidance and in-class reflection: A SQIRC-based mobile flipped learning approach to promoting students' billiards skills, strategies, motivation and self-efficacy. Comput. Educ. 2020, 160. [CrossRef]

46. Wasserman, N.H.; Quint, C.; Norris, S.A.; Carr, T. Exploring flipped classroom instruction in calculus III. Int. J. Innov. Sci. Math. 2017, 15, 545-568. [CrossRef]

47. Keith, T.Z. Multiple Regression and Beyond: An Introduction to Multiple Regression and Structural Equation Modeling, 2nd ed.; Routledge: London, UK, 2015.

48. Brown, M.B.; Forsythe, A.B. Robust tests for the equality of variances. J. Am. Stat. Assoc. 1974, 69, 364-367. [CrossRef]

49. Richardson, J.T.E. Eta squared and partial eta squared as measures of effect size in educational research. Educ. Res. Rev. 2011, 6, 135-147. [CrossRef]

50. Baia, B.; Shen, B.; Mei, H. Hong Kong primary students' self-regulated writing strategy use: Influences of gender, writing proficiency, and grade level. Stud. Educ. Eval. 2020, 65. [CrossRef]

51. Dörnyei, Z. Research Methods in Applied Linguistics: Quantitative, Qualitative, and Mixed Methodologies; Oxford University Press: Oxford, UK, 2007.

52. Cohen, J. Statistical Power Analysis for the Behavioural Sciences; Academic Press: New York, NY, USA, 1969.

53. Mertens, D.M. Research and Evaluation in Education and Psychology: Integrating Diversity with Quantitative, Qualitative, and Mixed Methods, 2nd ed.; Sage Publications: Thousand Oaks, CA, USA, 2005.

54. Ng, E.M.W. Integrating self-regulation principles with flipped classroom pedagogy for first year university students. Comput. Educ. 2018, 126, 65-74. [CrossRef]

55. Turra, H.; Carrasco, V.; Gonzalez, C.; Sandoval, V.; Yanez, S. Flipped classroom experiences and their impact on engineering students' attitudes towards university-level mathematics. High Educ. Teach. 2019, 4, 136-155. [CrossRef]

56. Yu, Z.; Wang, G. Learning achievements and satisfaction of the clicker-aided flipped business English writing class. Educ. Technol. Soc. 2016, 19, 298-312.

57. Xie, N.; Yang, Y.; Shen, H.T.; Zhao, T.T. Stroke-based stylization by learning sequential drawing examples. J. Vis. Commun. Image Represent. 2018, 51, 29-39. [CrossRef]

58. Rodrigues, R.L.; Sedraz, J.; Ramos, J.L.C.; de Souza, F.D.F.; Gomes, A.S. Uma Abordagem de Regressão Múltipla para Validação de Variáveis de Autorregulação da Aprendizagem em Ambientes de LMS. Braz. Symp. Comput. Educ. 2016, $27,916$.

59. Su, Y.S.; Chen, H.R. Social Facebook with big six approaches for improved students' learning performance and behavior: A case study of a project innovation and implementation course. Front. Psychol. 2020, 11, 1166. [CrossRef] [PubMed]

60. Zhang, J.H.; Zou, L.C.; Miao, J.J.; Zhang, Y.X.; Hwang, G.J.; Zhu, Y. An individualized intervention approach to improving university students' learning performance and interactive behaviors in a blended learning environment. Interact. Learn. Environ. 2020, 2, 231-245. [CrossRef] 
61. Su, Y.S.; Wu, S.Y. Applying data mining techniques to explore users behaviors and viewing video patterns in converged IT environments. J. Ambient Intell. Hum. Comput. 2021. [CrossRef]

62. Su, Y.S.; Suen, H.Y.; Hung, K.E. Predicting behavioral competencies automatically from facial expressions in real-time video recorded interviews. J. Real Time Image Process. 2021. [CrossRef]

63. Su, Y.S.; Ding, T.J.; Chen, M.Y. Deep learning methods in internet of medical things for valvular heart disease screening system. IEEE Internet Things J. 2021. [CrossRef] 